\title{
THIN FILM INTEGRATED RC-NETWORKS WITH COMPENSATED TEMPERATURE COEFFICIENTS OF R AND C
}

\author{
H. W. PÖTZLBERGER \\ Siemens AG, D-8000 München 70, Koppstraße 6, West Germany
}

(Received May 1, 1977)

\begin{abstract}
Thin film integrated RC-networks can be prepared from two non reactiveiy sputtered TaAl films, the properties and optimum compositions of which have been found. Temperature compensation of the integrated resistors and capacitors is achieved by adjusting the temperature coefficient of capacitance. A duplex dielectric capacitor structure is used with anodically formed $\mathrm{TaAl}$-oxide and a sputtered $\mathrm{SiO}_{2}$ layer. Temperature coefficient of capacitance, dielectric loss and capacitance density have been measured vs. $\mathrm{SiO}_{2}$ thickness. Because of almost linear dependences on temperature of both the $\mathrm{TaAl}$ resistors and the $\mathrm{TaAl}$-oxide $/ \mathrm{SiO}_{2}$-capacitors, such $\mathrm{RC}$-networks show temperature compensation over a wide temperature range, the TCC being $+110 \mathrm{ppm} / \mathrm{K}$ and the TCR $-110 \mathrm{ppm} / \mathrm{K}$.
\end{abstract}

\section{INTRODUCTION}

Thin film integrated resistor- and capacitor-networks are expanding into the electronic market because of a high standard of miniaturization, high stability and high precision. Important applications are active filters with temperature compensation. Temperature compensation, i.e. matching of TCR and TCC is usually achieved by altering the resistive film properties. In the well known $\beta-\mathrm{Ta} / \mathrm{Ta}_{2} \mathrm{~N}$ technology, ${ }^{1}$ the TCR of the highly stable $\mathrm{Ta}_{2} \mathrm{~N}$, which is about $-70 \mathrm{ppm} / \mathrm{K}$, is lowered by reactive sputtering of Ta with both oxygen and nitrogen to give a TCR of $-200 \mathrm{ppm} / \mathrm{K}$, which compensates for the positive TCC of $\beta$-Ta oxide capacitors. A possible way of decreasing the TCC of $\beta$-Ta oxide is to use a sandwich dielectric structure, consisting of anodic $\beta$-Ta oxide and sputtered $\mathrm{SiO}_{2}$. An improvement of capacitor yield and long term stability and a reduction of capacitance density, as compared to $\beta$-Ta oxide capacitors, have been reported. ${ }^{2}$

This paper will be concerned on temperature compensated $\mathrm{TaAl}$ thin film $\mathrm{RC}$-networks.

\section{TaAl RC-NETWORKS}

Thin film integrated resistors and capacitors can be prepared from a single $\mathrm{TaAl}$ film or from two $\mathrm{TaAl}$ layers with different alloy compositions. RC-networks made of a single $\mathrm{TaAl}$ film cannot be fabricated with higher sheet resistivities. A TaAl double layer technique has to be applied then for RC-fabrication, where the resistors are made of a high resistivity $\mathrm{TaAl}$ alloy, whereas $\mathrm{TaAl}$ oxide capacitors are prepared from a low resistivity $\mathrm{TaAl}$ alloy. ${ }^{3}$ In this case both high resistance values of the resistors and a low series resistance of the capacitor base electrode can be achieved.

To account for temperature compensation either reactive sputtering means or duplex dielectric capacitors have also to be introduced into this technology. Adjustment of the TCR in a similar way as in conventional Ta-technology is possible, but will not be discussed in this paper, since we did not want to lose the main advantage of $\mathrm{TaAl}$ technology, i.e. the non reactive sputtering process. We have investigated $\mathrm{TaAl}$ oxide $/ \mathrm{SiO}_{2}$ duplex dielectric capacitors with respect to temperature compensation and their compatibility with a TaAl-RC-fabrication process, where the $\mathrm{TaAl}$ films can be sputtered without using reactive gases.

The optimum compositions of the TaAl double layer have been found out, also the conditions necessary for temperature compensation, when TaAl oxide $/ \mathrm{SiO}_{2}$ capacitors are used.

\subsection{TaAl Resistors}

TaAl films with $\mathrm{Al}$ contents from 8 to 98 at. \% have been investigated. They were sputtered in an a.c. rod sputtering system. ${ }^{4}$ The sputtering parameters were: 
argon pressure $10^{-2}$ Torr, a.c. voltage $3,5 \mathrm{kV}$, a.c. current $0,45 \mathrm{~A}$, sputtering rate $25-30 \mathrm{~nm} / \mathrm{min}$. Some results are given in Figures 1 to 4. In the far Ta-region a tetragonal structure has been found, similar to that of $\beta-\mathrm{Ta}$, with high resistivities and a low film density, which can be attributed to the relatively low sputtering voltage. This region is not very interesting for resistor fabrication using these sputtering conditions, since the $\rho$-values decrease with film thickness. This is not the case for the amorphous $\mathrm{TaAl}$ films above 30 at. \% Al. Their resistivities and TCR's are, moreover, almost insensitive to $\mathrm{Al}$ content between 30 and 65 at. \% $\mathrm{Al}$, as seen in Figures 1 and 2. Figure 3 shows the

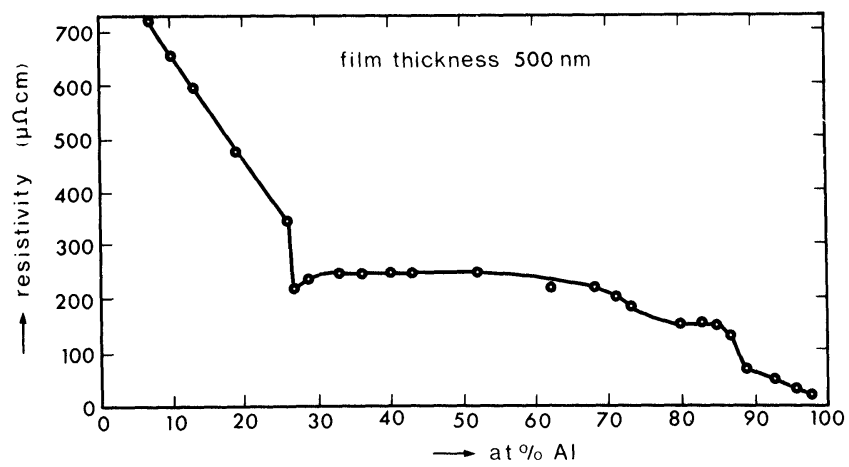

FIGURE 1 Resistivity of TaAl.

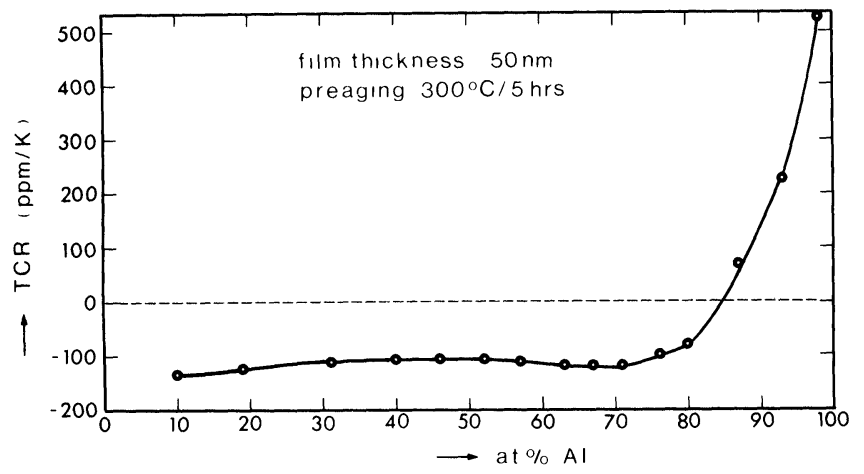

FIGURE 2 TCR of TaAl.

resistivity and the TCR vs. film thickness for a 60 at. $\% \mathrm{Ta} / 40$ at. $\% \mathrm{Al}$ alloy film. Taking into account also the excellent ageing behaviour, which is shown in Figure 4 for the whole TaAl system, we have chosen this composition as best suited resistor material. Its resistivity is $250 \pm 10 \mu \Omega \mathrm{cm}$ and its TCR is $-110 \pm$ $10 \mathrm{ppm} / \mathrm{K}$ for film thicknesses between 25 and 500 nm. A Al-rich TaAl alloy with 7 at. $\% \mathrm{Ta} / 93$ at. \% $\mathrm{Al}$ is used as capacitor base electrode material, because of its low resistivity, which is about $50 \mu \Omega \mathrm{cm}$ and its good capacitor properties reported elsewhere. ${ }^{5}$ The capacitance density of $200 \mathrm{~V}$ anodized films of this compositions is $34 \mathrm{nF} / \mathrm{cm}^{2}$, their TCC is about $+500 \mathrm{ppm} / \mathrm{K}$.

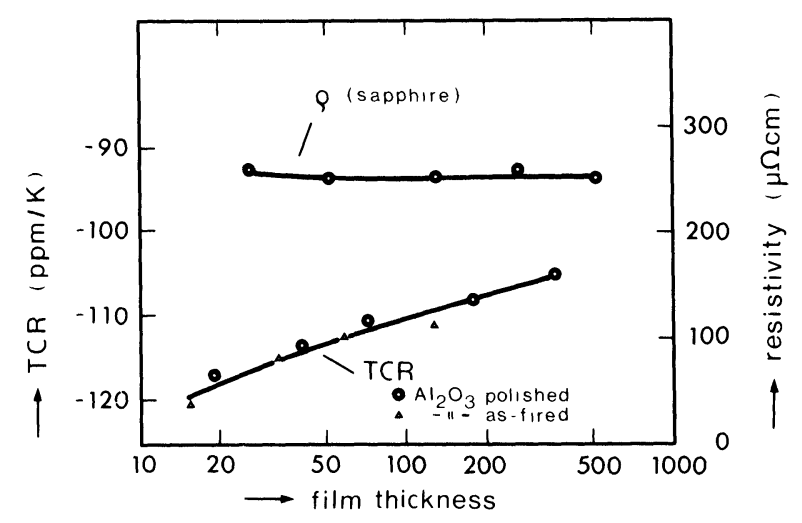

FIGURE 3 TCR and $\rho$ (resistivity) of TaAl 60/40.

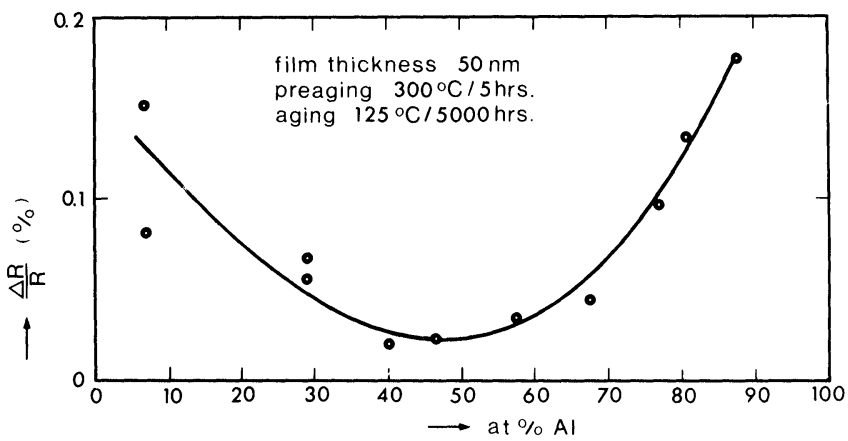

FIGURE 4 Resistance change of TaAl.

\subsection{TaAl-Oxide $/ \mathrm{SiO}_{2}$ Capacitors}

For temperature compensation a $\mathrm{SiO}_{2}$ layer is sputtered on top of the anodically formed $\mathrm{TaAl}$ oxide dielectric by r.f. sputtering from a quartz target. Typical sputtering parameters are: argon pressure $10^{-2}$ Torr, r.f. power $500 \mathrm{~W}$, r.f. voltage $1,5 \mathrm{kV}$, sputtering rate $9 \mathrm{~nm} / \mathrm{min}$. The influence of $\mathrm{SiO}_{2}$ thickness on the TCC, the dielectric loss and the capacitance density can be seen in Figures 5 and 6. Temperature compensation with the integrated resistors is achieved with a $230 \mathrm{~nm}$ thick $\mathrm{SiO}_{2}$ layer. The TCC of such a duplex dielectric capacitor is +110 $\pm 10 \mathrm{ppm} / \mathrm{K}$, the tangent $\delta$ is $0,10 \%$ and its capacitance density is $8,5 \mathrm{nF} / \mathrm{cm}^{2}$, if a $200 \mathrm{~V}$-TaAl-oxide is used as the first dielectric layer. 


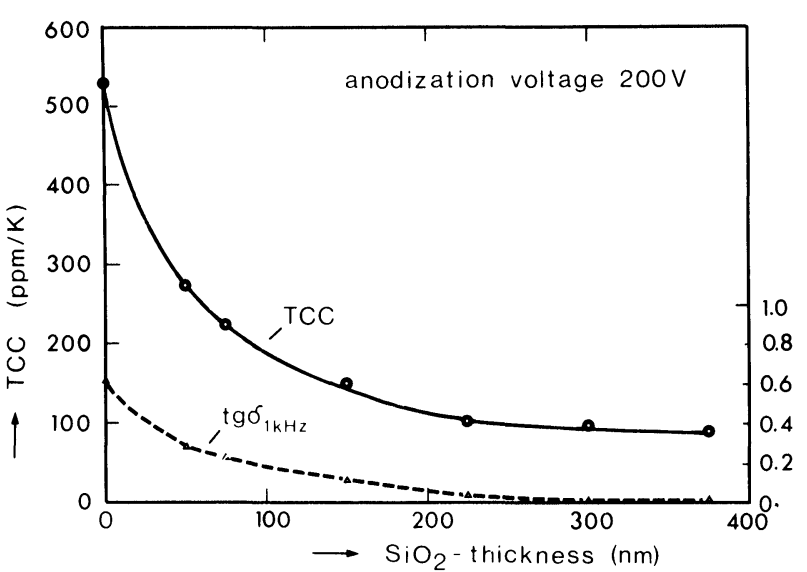

FIGURE 5 TCC and tangent $\delta$ vs. $\mathrm{SiO}_{2}$ thickness.

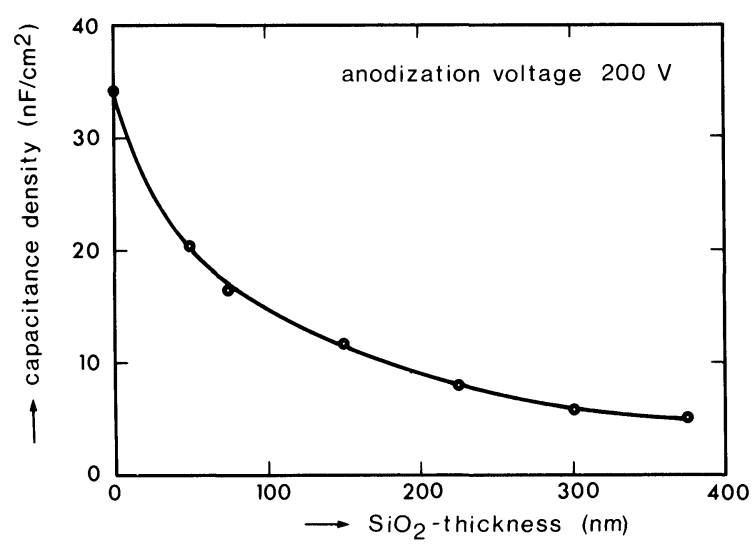

FIGURE 6 Capacitance density vs. $\mathrm{SiO}_{2}$ thickness.

\section{TEMPERATURE COMPENSATED TaAl/ $/ \mathrm{SiO}_{2}$ RC-NETWORKS}

The duplex dielectric TaAl-oxide $/ \mathrm{SiO}_{2}$ capacitor can be easily integrated into the fabrication process of TaAl R-networks. ${ }^{6,7}$ A schematical view of the RCstructure is given in Figure 7.

Temperature compensation in $\mathrm{TaAl} / \mathrm{SiO}_{2}$ technology is easier to achieve than in conventional Tatechnology mainly for three reasons: the more simple non reactive sputtering process itself, the lower absolute value of the temperature coefficients of the components and, as a consequence, a better linearity of resistance and capacitance with temperature. We have examined the temperature compensation of $\mathrm{TaAl} / \mathrm{SiO}_{2} \mathrm{RC}$-networks in a broad temperature range between $-55^{\circ} \mathrm{C}$ and $+125^{\circ} \mathrm{C}$ (Figure 8). Both resistance and capacitance are almost linearly dependent on temperature. Taking into account the
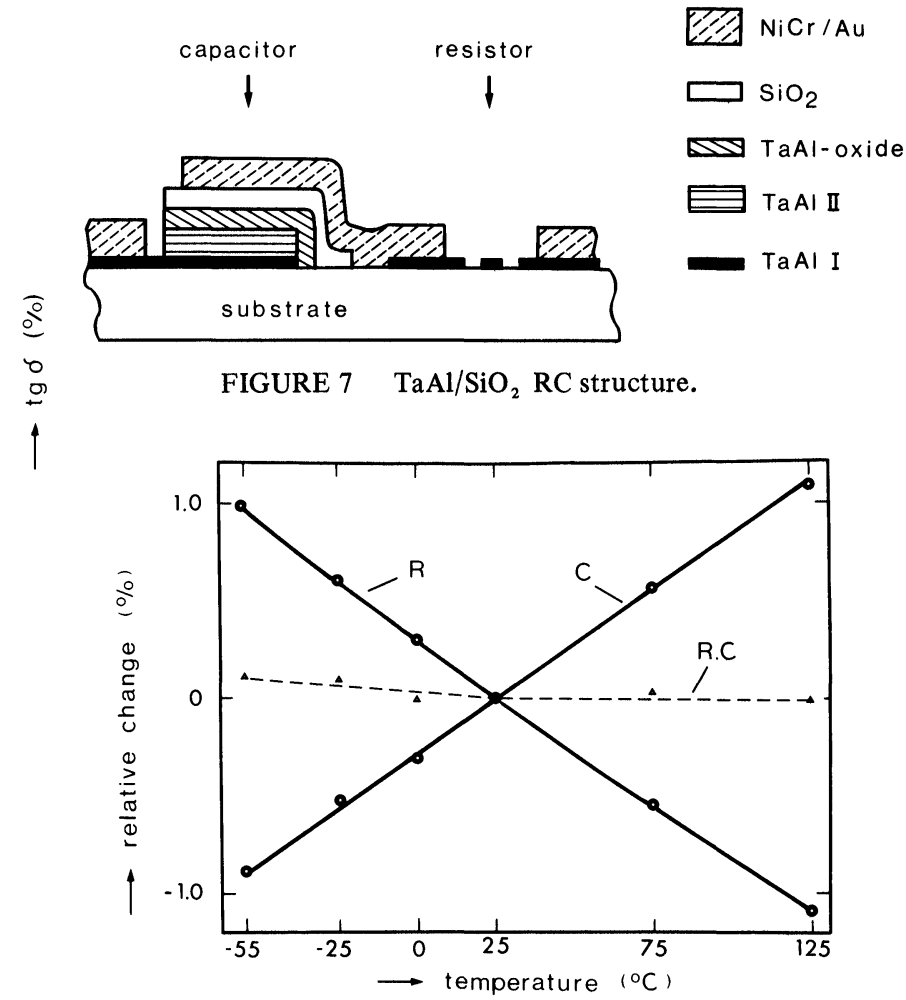

FIGURE $8 \frac{\Delta R}{R}, \frac{\Delta C}{C}$ and $\frac{\Delta R C}{R C}$ vs. temperature.

measuring accuracy of $\pm 5 \mathrm{ppm} / \mathrm{K}$, the RC-product, the relative change of which is also delineated in the figure, is nearly constant over the whole temperature interval. Another advantage of RC technology is good reproducibility, since non reactive sputtering processes only are applied. Because of weak dependences of the TCR and the TCC on film thicknesses (see Figures 3 and 5) both sheet resistivity and capacitance density can be varied to some extent without giving up temperature compensation.

\section{CONCLUSION}

Integrated RC-networks have been prepared, using a non reactively sputtered $\mathrm{TaAl}$ double layer and r.f. sputtered $\mathrm{SiO}_{2}$. The TaAl oxide $/ \mathrm{SiO}_{2}$ duplex dielectric capacitor structure shows low tangent $\delta$ values and a TCC, which compensates for the TCR of the 60 at. $\% \mathrm{Ta} / 40$ at. \% $\mathrm{Al}$ alloy film in a broad temperature range. Together with the simple fabrication process the $\mathrm{TaAl} / \mathrm{SiO}_{2}$ technology is a real alternative to the more sophisticated $\beta-\mathrm{Ta} / \mathrm{Ta}_{2} \mathrm{~N}$ technology. 
This work has been supported under the technological programme of the Federal Department of Research and Technology of the FRG. The author alone is responsible for the contents.

\section{REFERENCES}

1. R. W. Berry, P. M. Hall and M. T. Harris, Thin Film Technology, V. Nostrand Comp., 1968, p. 387.
2. S. Sato, A. Sato and E. Okamoto, Proc. El. Comp. Conf., 1973, Wash. D.C.

3. DPA Offenlegungsschrift Nr. 2331586 v. 20.6.73.

4. C. A. Steidel, D. Jaffe and H. Y. Kumagai, J. Vac. Sci. Technol., 9 (1971) 1, 346.

5. A. Schauer, M. Roschy and W. Juergens, Thin Solid Films, 27 (1975), 111-121.

6. DPA Nr. P 2653814.7, v. 26.11.76.

7. W. D. Münz and H. W. Pötzlberger, to be published. 

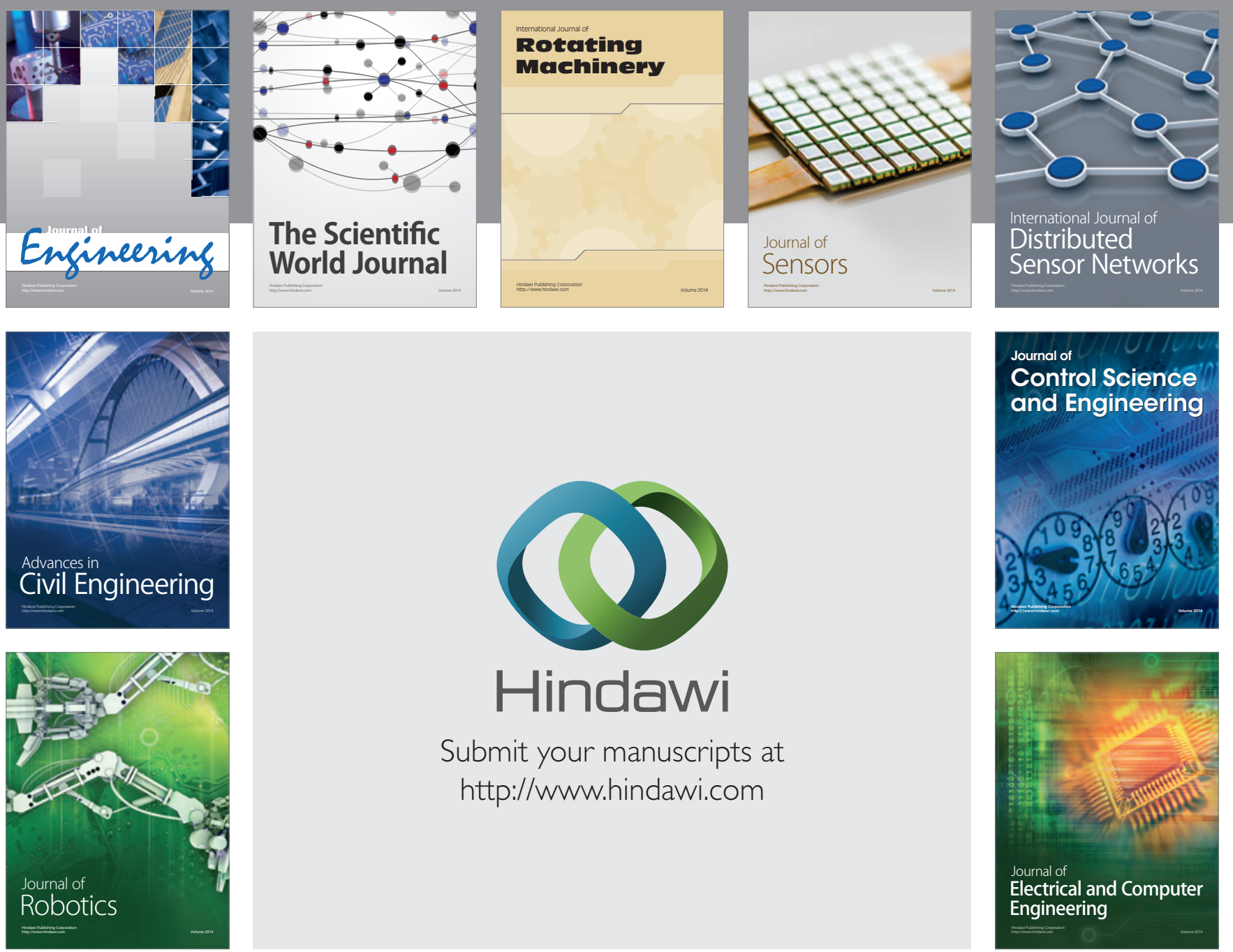

Submit your manuscripts at

http://www.hindawi.com
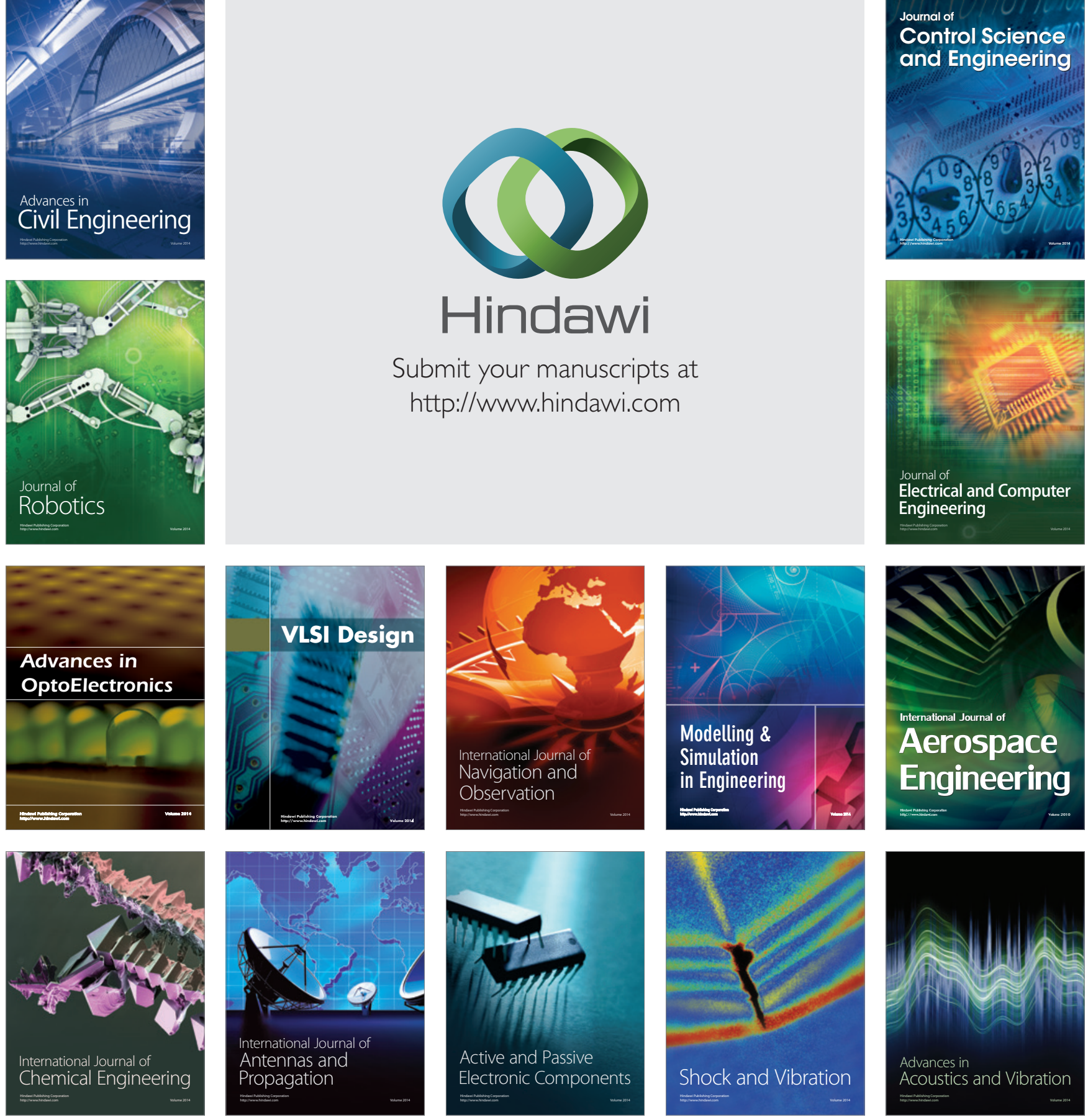